\title{
Brain morphology and physical symptoms: a population-neuroimaging study in
}

\section{3,250 pre-adolescents}

Fernando Estévez-López a, Hannah H. Kim ${ }^{\text {b }}$, Monica López-Vicente ${ }^{\text {a }}$, Jeroen S. Legerstee $^{\text {a }}$, Manon H. J. Hillegers ${ }^{\text {a }}$, Henning Tiemeier ${ }^{\mathrm{a}, \mathrm{b}}$, Ryan L. Muetzel ${ }^{\mathrm{a}}$

a Department of Child and Adolescent Psychiatry/Psychology, Erasmus MC University Medical Centre, Rotterdam, The Netherlands.

${ }^{b}$ Department of Social and Behavioral Sciences, Harvard T. H. Chan School of Public Health, Boston, MA, USA

ORCID list: F.E.-L., $\quad$ https://orcid.org/0000-0003-2960-4142; $\quad$ H.H.K., https://orcid.org/0000-0002-9640-7299; M.L.-V., https://orcid.org/0000-0002-50907538; J.S.L., http://orcid.org/0000-0001-6793-1123; M.H.J.H, http://orcid.org/0000-

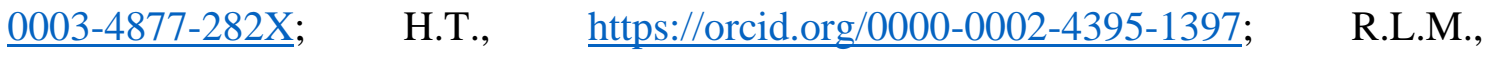
https://orcid.org/0000-0003-3215-1287.

* Corresponding author:

Fernando Estévez-López

Department of Child and Adolescent Psychiatry/Psychology, Erasmus MC University Medical Centre, Rotterdam, The Netherlands.

f.estevez-lopez@erasmusmc.nl 


\section{ABSTRACT}

Physical symptoms are defined as symptoms for which adequate examination does not reveal a sufficient underlying root cause, e.g., pain and fatigue. The extant literature of the neurobiological underpinnings of physical symptoms has been largely inconsistent and primarily consists of (clinical) case-control studies with relatively small samples sizes. Therefore, we studied the association of brain morphology with physical symptoms in pre-adolescents from two independent and population-based cohorts. This study included 2,683 individuals from the Generation R Study (51\% girls, $10.1 \pm 0.6$ years old) and 10,567 pre-adolescents from the ABCD Study (48\% girls, $9.9 \pm 0.6$ years old). Highresolution structural magnetic resonance imaging (MRI) was collected using 3-Tesla MRI systems. Physical symptoms were evaluated using the somatic complaints syndrome scale from the parent-reported school-age version of the Child Behavior Checklist. Linear regression models were fitted for global brain metrics (i.e., cortical and subcortical grey matter volume and total white matter volume) as well as surface-based vertex-wise measures (surface area and cortical thickness). Analyses were initially conducted separately in each cohort and later meta-analysed. No associations were observed in either cohort separately. In the combined vertex-wise meta-analysis of both cohorts; the right hemisphere surface area, most notably the rostral middle frontal gyrus, superior frontal gyrus and anterior cingulate cortex, were related to physical symptoms after correcting for multiple comparisons (cluster area $=1,882 \mathrm{~mm}^{2}$ ). The present study, which is the most representative and well-powered to date, suggests that surface area, but not other measures of brain morphology, are modestly related to physical symptoms in preadolescents. While these effects are subtle, future longitudinal research is warranted to elucidate whether such associations indicate a cause or a consequence of the physical symptoms.

Keywords: Cohort studies; Epidemiology; Gray matter; Neuroimaging; Paediatrics; Psychiatric symptoms; QDECR; Vertex-wise analysis. 


\section{INTRODUCTION}

Physical symptoms are defined as symptoms for which adequate examination does not reveal a sufficient underlying root cause. Physical symptoms are also known as somatic symptoms and medically unexplained physical symptoms (Creed et al., 2010). Physical symptoms are mostly related to the presence of pain, fatigue and functional disturbances in organ systems such as dizziness or bowel symptoms (Henningsen et al., 2007). The estimated prevalence of physical symptoms in children and adolescents is high; ranging from $18 \%$ and $31 \%$ (Berntsson and Köhler, 2001). In some youth, physical symptoms become persistent and disabling, which imposes a burden on individuals, families, and the health system. For instance, persistent physical symptoms in young are related to increased health care costs (Groenewald et al., 2014) and school absences (Gubbels et al., 2019).

Central sensitisation, or neurobiological alterations in general, is the most widely speculated cause of persistent physical symptoms (Bourke et al., 2015; den Boer et al., 2019). Neuroimaging methods, such magnetic resonance imaging (MRI), enable to evaluate the activity and structure of the brain and its relationship with these symptoms. To date, most of the previous neuroimaging studies were conducted using structural brain imaging data in small sample sizes in adults. Results in general did not replicate in subsequent research in independent samples (Boeckle et al., 2016) with a number of exceptions. In comparison to peers without symptoms, children with persistent physical symptoms have shown lower grey matter volume in the cingulate cortex (Bhatt et al., 2019; Boeckle et al., 2016) and prefrontal cortex (Bhatt et al., 2019; Hubbard et al., 2016). Cortical volume is determined through the cortical thickness (i.e., the distance between white matter and pial surfaces) and the surface area (composed of the convex hull area and the area of cortex hidden in sulci), which are shown to be accurate measures for examining deviations in typical brain development (Raznahan et al., 2011). Particularly, exploring the role of cortical thickness and surface area in the development of physical symptoms might help to understand whether volumetric differences are driven by associations with cortical thickness, surface area or both.

Although the research is inspiring and informative, most of the studies have relied on comparing brain morphology between small samples of people with and without a clinical diagnosis of a specific physical symptom disorder (i.e., case-control studies in specific 
disorders). However, physical symptoms lie on a continuum in the general population (Henningsen et al., 2007; Richardson and Engel, 2004; Wolfe et al., 2013). Thus, dimensional approaches are needed in the search for neurobiological features which are associated with the symptoms. In addition to improving our understanding of physical symptoms along a continuum, population-based cohort studies offer larger samples which may help overcome the inconsistencies in the literature and to identify new brain features associated with physical symptoms. The association of brain structure with early symptoms in undiagnosed and untreated persons is of interest, because any neuroplasticity related to persistent physical symptoms is expected to be negligible in this population. Thus, the aim of this population-neuroimaging study was to examine the association of brain structure with dimensional physical symptoms in pre-adolescents from two large, independent population-based cohorts. On the basis of previous evidence, we hypothesise that lower grey matter volumes in the cingulate cortex (Bhatt et al., 2019; Boeckle et al., 2016) and prefrontal cortex (Bhatt et al., 2019; Hubbard et al., 2016) and supplementary motor cortex (Hubbard et al., 2016; Kutch et al., 2017) are associated with more physical symptoms. It remains open whether the hypothesis will be confirmed for cortical thickness, surface area or both.

\section{METHODS}

\section{Design}

This cross-sectional study was embedded in two independent population-based cohorts: (i) the Generation R Study, the Netherlands and (ii) Adolescent Brain Cognitive Development (ABCD) Study, USA.

\section{Participants}

The Generation R Study is a population-based cohort of maternal and child health from foetal life onward. A detailed description of the Generation $\mathrm{R}$ study is available (Kooijman et al., 2016). Briefly, between March 2013 and November 2015, participants aged 8 to 12 years visited a study-dedicated research centre for a detailed behavioural assessment (Kooijman et al., 2016) and also underwent MRI scan (White et al., 2018). Of the 3992 children who visited our research centre, 3265 participants have data on both physical symptoms and MRI, and 2,683 datasets were available for statistical analyses. 
Figure 1 illustrates the exclusions in detail. The Medical Ethics Committee of the Erasmus Medical Center approved all study procedures (Approval number: MEC-2012-165NL40020.078.12), and all caregivers provided written informed consent.

The ABCD Study is a population-based cohort study of brain development and child health. We used data from the baseline assessment (release 2.0.1) of the ABCD Study (Volkow et al., 2018). An extensive description of the study is provided elsewhere (Garavan et al., 2018; Volkow et al., 2018). Briefly, participants in the ABCD study were recruited at 21 sites across the United States. The baseline cohort of the ABCD study includes data from 11,875 children between 9 and 10 years of age. Of them, 10,567 participants have data on both physical symptoms and MRI and were included the final sample. Figure 1 illustrates the flowchart of participants. Centralized institutional review board (IRB) approval was obtained from the University of California, San Diego, USA. Study sites obtained approval from their local IRBs. Written, informed consent and assent were provided by each parent and child, respectively.

\section{Neuroimaging: brain structure}

Detailed descriptions of the scan protocol, imaging procedures, and subsequent processing of the imaging data of the Generation R (Muetzel et al., 2019; White et al., 2018) and ABCD (Casey et al., 2018; Hagler et al., 2019) studies are available. Briefly, both studies performed high-resolution structural MRI that were collected using 3-Tesla MRI systems. Data quality assurance was a multi-step process including both manual review by trained technicians and automated software (Hagler et al., 2019; Muetzel et al., 2019). Data from both cohorts were processed through FreeSurfer (version 6.0) on the same high-performance computing system. Surface-based maps of surface area and cortical thickness were co-registered to a common stereotactic space, and smoothed with a 10mm full width half max Gaussian kernel.

\section{Physical symptoms}

In both the Generation R study and ABCD study, mother-reported data on the somatic complaints syndrome subscale from the school-age version (for ages 6 to 18) of the Child Behavior Checklist (CBCL) was used to assess child physical symptoms (Achenbach and Rescorla, 2000). The CBCL is a validated and reliable inventory that uses caregiver- 
reported information to assess behavioural problems in children (Ivanova et al., 2010). The caregivers rated behaviour problems of the child in the previous 6 months using a three-point Likert scale ( $0=$ not true, $1=$ somewhat true, $2=$ very true). The CBCL is composed by 7 subscales. The somatic complaints subscale includes the presence of the following signs: (i) nightmares, (ii) constipation, doesn't move bowels, (iii) dizziness, (iv) overtiredness without a good reason, and (v) physical problems without known medical cause: headaches, stomach aches, other aches/pain, nausea/feels sick, problems with eyes (not if corrected by glasses), rashes/skin problems and vomiting/throwing up. The scores of the CBCL somatic complaints subscale range from 0 to 22 , with higher scores indicating more physical symptoms.

\section{Potential confounders}

Age (in years old), sex (boy or girl), ethnicity, mother education for Generation R and parental education for $\mathrm{ABCD}$, monthly household income, body mass index (BMI, calculated as weight $(\mathrm{kg}) /$ height $\left(\mathrm{m}^{2}\right)$ ) and non-verbal intelligence quotient (IQ) were assessed in the Generation R study and ABCD study.

\section{Statistical analyses}

Analyses were run using the R statistical software (version 3.4.3). For the global brain structure metrics, we conducted a set of separate linear regression models with brain structure as the independent variable and physical symptoms (continuous somatic complaints syndrome subscale from the CBCL, square root transformed) as the dependent variable. The model was adjusted for estimated intracranial total volume, age, sex, ethnicity, mother/paternal education, household income, BMI and IQ.

Surface-based vertex-wise analyses were conducted using the $\mathrm{R}$ package QDECR (Lamballais and Muetzel, 2021). At each cortical vertex, we examined the association of cortical thickness and surface area with physical symptoms. The model included the same covariates as the model for the global brain structure described above, except that estimated intracranial total volume was not included. Resulting p-value maps were corrected for multiple comparisons at the vertex level using Gaussian Monte Carlo Simulations (Hagler et al., 2006). Surface-based analyses may show non-Gaussian patterns of spatial correlations, which would increase the false positive rate higher than 
0.05. We therefore set the cluster forming threshold to $\mathrm{p}=0.001$, as this has shown high correspondence with actual permutation testing across all surface measures (Greve and Fischl, 2018). We further applied Bonferroni correction to account for analysing both hemispheres separately (i.e. $\mathrm{p}<0.025$ cluster-wise). Surface-based vertex-wise analyses were conducted first in each cohort separately. Next, the results from both cohorts were pooled using meta-analyses.

Missing covariate data were observed: (i) in the Generation R study for ethnicity, body mass index, maternal education (all, $\leq 1 \%$ ) and monthly household income and non-verbal intelligence quotient (both, $\sim 10 \%$ ) and (ii) in the ABCD study for BMI, race/ethnicity, parental education (all, $\leq 1 \%$ ) and non-verbal intelligence quotient (2.2\%). Missing covariate data were estimated by multiple imputation with the R package MICE (van Buuren and Groothuis-Oudshoorn, 2011). With 100 iterations, a total of 40 imputed datasets were generated, and results were pooled using Rubin's rules (Rubin, 2004).

\section{RESULTS}

Figure 1 illustrates the flowchart of participants. In the Generation R cohort, 3,992 participants were recruited. Of these, 727 (18\%) were excluded due to incomplete assessments, $18(0.4 \%)$ due to incidental MRI findings, and $564(14 \%)$ because of unusable MRI data. In the ABCD cohort, 11,875 participants were included at baseline (the 2.0.1 curated release). Of these, $846(7.1 \%)$ and $462(3.9 \%)$ were excluded because of incomplete assessments or poor FreeSurfer quality control, respectively (see Figure 1 for details).
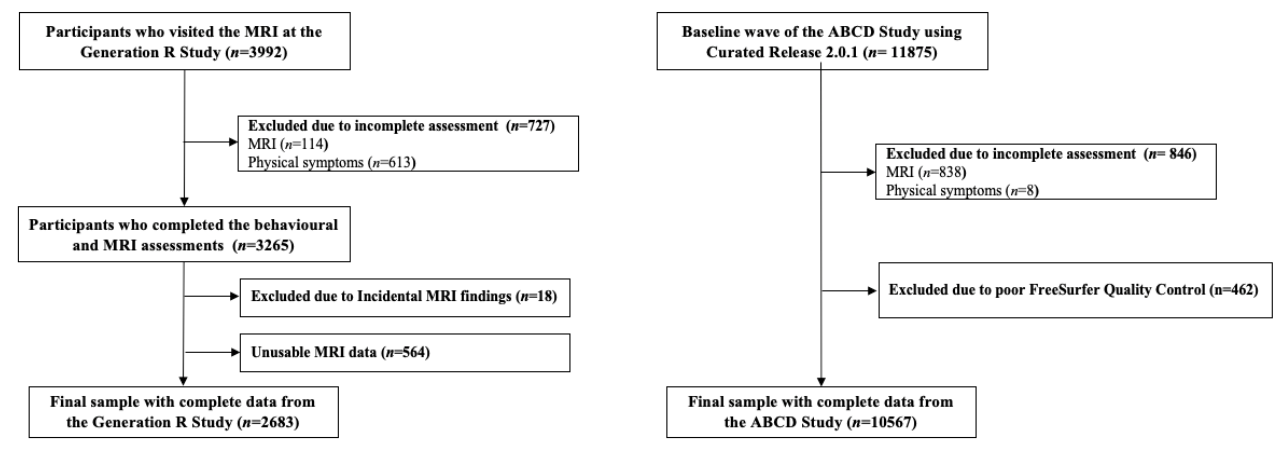

Figure 1. Flowchart of participants.

ABCD, Adolescent Brain Cognitive Development. MRI, magnetic resonance imaging. 
The final total sample of the present study comprised 13,250 participants. Table 1 shows the characteristics of 2,683 participants from the Generation R cohort, most were of Dutch national origin (65.8\%). Table 2 shows the characteristics of 10,567 participants from the ABCD cohort. The majority of the participants were of Non-Hispanic White ethnicity (52.9\%), Hispanic (20.3\%) or Black (14.5\%) race/ethnicity.

Table 1. Characteristics of the participants in the Generation R study $(n=2,683)$.

\begin{tabular}{lrr} 
& Mean & SD \\
\hline Age & 10.1 & 0.6 \\
Body mass index & 17.4 & 2.5 \\
Non-verbal intelligence quotient & 103.8 & 14.7 \\
Physical symptoms (CBCL) & 1.5 & 2.0 \\
\hline & $\mathrm{N}$ & $\%$ \\
\hline Sex, female & 1356 & 50.5 \\
National origin & & \\
Dutch & 1747 & 65.1 \\
Caribbean & 225 & 8.4 \\
Non-Dutch Western & 225 & 8.4 \\
Non-Western: Moroccan or Turkish & 213 & 7.9 \\
African & 124 & 4.6 \\
Non-Western: American or Asian & 108 & 4.0 \\
Indonesian & 15 & 0.6 \\
Missing data & 26 & 1.0 \\
Maternal education level & & \\
No/Primary/Secondary studies & 1773 & 66.1 \\
Higher education & 879 & 32.8 \\
Missing data & 26 & 1.1 \\
Monthly household income & & \\
$\leq € 2,000$ & 384 & 14.3 \\
$>$ 2,000 to $\leq 3,200$ & 611 & 22.8 \\
> 3,200 & 1364 & 50.8 \\
Missing data & 324 & 12.1 \\
\hline
\end{tabular}

Note. Non-imputed data are shown. CBCL, the child behavior checklist. SD, standard deviation. 
Table 2. Characteristics of the participants in the ABCD study $(n=10,567)$.

\begin{tabular}{|c|c|c|}
\hline & \multirow[b]{2}{*}{ Mean } & \multirow[b]{2}{*}{$\mathrm{SD}$} \\
\hline & & \\
\hline Age & 9.9 & 0.6 \\
\hline Body mass index & 18.7 & 3.9 \\
\hline WISC-V Matrix Reasoning Total Score & 9.9 & 3.0 \\
\hline \multirow[t]{2}{*}{ Physical symptoms (CBCL) } & 1.5 & 2.0 \\
\hline & $\mathrm{N}$ & $\%$ \\
\hline Sex, female & 5046 & 47.8 \\
\hline \multicolumn{3}{|l|}{ Race/ethnicity } \\
\hline White & 5586 & 52.9 \\
\hline Black & 1532 & 14.5 \\
\hline Hispanic & 2150 & 20.3 \\
\hline Asian & 213 & 2.0 \\
\hline Other & 1072 & 10.1 \\
\hline Missing data & 14 & 0.1 \\
\hline \multicolumn{3}{|l|}{ Highest parental education } \\
\hline$<$ High School Diploma & 502 & 4.8 \\
\hline High School Diploma/GED & 987 & 9.3 \\
\hline Some College & 2752 & 26.0 \\
\hline Bachelor & 2695 & 25.5 \\
\hline Post Graduate Degree & 3619 & 34.2 \\
\hline Missing data & 12 & 0.1 \\
\hline \multicolumn{3}{|l|}{ Monthly household income } \\
\hline Low & 2820 & 26.7 \\
\hline Middle & 2762 & 26.1 \\
\hline High & 4102 & 38.8 \\
\hline Missing data & 883 & 8.4 \\
\hline
\end{tabular}

Note. Non-imputed data are shown. CBCL, the child behavior checklist. SD, standard deviation. GED, General Educational Development.

Table 3 shows regression analyses for the association of physical symptoms and the global metrics of brain structure. None of the associations were statistically significant and, in general, the unstandardised regression coefficients were small. For example, in the Generation R, for every unit increase in physical symptoms (square root transformed), there was a $6.4 \times 10^{-4} \mathrm{~cm}^{3}$ decrease in cortical grey matter volume. Similarly, for ABCD, for every unit increase in physical symptoms (square root transformed), there was a 3.2 $\mathrm{x} 10^{-4} \mathrm{~cm}^{3}$ decrease in total white matter volume. Meta-analysis confirmed the lack of statistically significant associations between the global metrics of brain structure and physical symptoms (all, p-values $\geq 0.4$ ). 
Table 3. Associations of brain structure with physical symptoms.

\section{Generation R study $(\mathrm{N}=2,683)$}

\begin{tabular}{|c|c|c|c|c|c|c|c|c|c|c|c|c|}
\hline & \multicolumn{4}{|c|}{ Cortical grey matter volume $\left(\mathrm{cm}^{3}\right)$} & \multicolumn{4}{|c|}{ Subcortical grey matter volume $\left(\mathrm{cm}^{3}\right)$} & \multicolumn{4}{|c|}{ Total white matter volume $\left(\mathrm{cm}^{3}\right)$} \\
\hline & $\mathrm{b}$ & SE & $\mathrm{p}_{\text {unc }}$ & $\mathrm{p}_{\mathrm{FDR}}$ & $\mathrm{b}$ & SE & $\mathrm{p}_{\text {unc }}$ & $\mathrm{p}_{\mathrm{FDR}}$ & $\mathrm{b}$ & SE & $\mathrm{p}_{\text {unc }}$ & $\mathrm{p}_{\mathrm{FDR}}$ \\
\hline \multirow[t]{4}{*}{ Physical symptoms } & $-6.4 \times 10^{-4}$ & $6.5 \times 10^{-4}$ & 0.327 & 0.944 & $1.9 \times 10^{-2}$ & $1.1 \times 10^{-1}$ & 0.866 & 0.944 & $-3.3 \times 10^{-4}$ & $7.4 \times 10^{-4}$ & 0.654 & 0.944 \\
\hline & \multicolumn{12}{|c|}{ ABCD study $(\mathrm{N}=10,567)$} \\
\hline & \multicolumn{4}{|c|}{ Cortical grey matter volume $\left(\mathrm{cm}^{3}\right)$} & \multicolumn{4}{|c|}{ Subcortical grey matter volume $\left(\mathrm{cm}^{3}\right)$} & \multicolumn{4}{|c|}{ Total white matter volume $\left(\mathrm{cm}^{3}\right)$} \\
\hline & B & SE & $\mathrm{p}_{\text {unc }}$ & p pDR & $\mathrm{b}$ & SE & $\mathrm{p}_{\text {unc }}$ & $\mathrm{p}_{\mathrm{FDR}}$ & $\mathrm{b}$ & SE & $\mathrm{p}_{\text {unc }}$ & $\mathrm{p}_{\mathrm{FDR}}$ \\
\hline Physical symptoms & $-2.1 \times 10^{-5}$ & $2.5 \times 10^{-4}$ & 0.933 & 0.937 & $-6.9 \times 10^{-4}$ & $3.1 \times 10^{-3}$ & 0.820 & 0.937 & $-3.2 \times 10^{-4}$ & $3.1 \times 10^{-4}$ & 0.299 & 0.784 \\
\hline
\end{tabular}

Note. b, unstandardised coefficient regression; SE, standard error; unc, uncorrected; FDR, False Discovery Rate.

The model was adjusted for age, sex, ethnicity, estimated intracranial volume, mother education, body mass index and non-verbal intelligence quotient. Physical symptoms were assessed using the school-age version (for ages 6 to 18) of the Child Behavior Checklist (CBCL). 
In order to determine whether there were any focal associations between brain structure and physical symptoms, we used a stepped approach. First, whole-brain vertex wise analyses were conducted in each cohort separately. We found no associations between brain structure (i.e. surface area and cortical thickness) and physical symptoms in the individual cohorts after adjusting for multiple comparisons. Second, we pooled results from both cohorts using meta-analyses. Figure 2 shows that physical symptoms were related to surface area in five clusters in the right hemisphere. The largest cluster had a size of $1468 \mathrm{~mm}^{2}$, with $98 \%$ of the vertices in the frontal lobe. The second largest cluster was $204 \mathrm{~mm}^{2}$, and was located primarily in the temporal lobe (e.g., the middle temporal gyrus, inferior temporal gyrus). Two small clusters were found in the caudal anterior cingulate cortex (total area $104 \mathrm{~mm}^{2}$ ), and another was observed in the rostral anterior cingulate cortex $\left(46 \mathrm{~mm}^{2}\right)$.

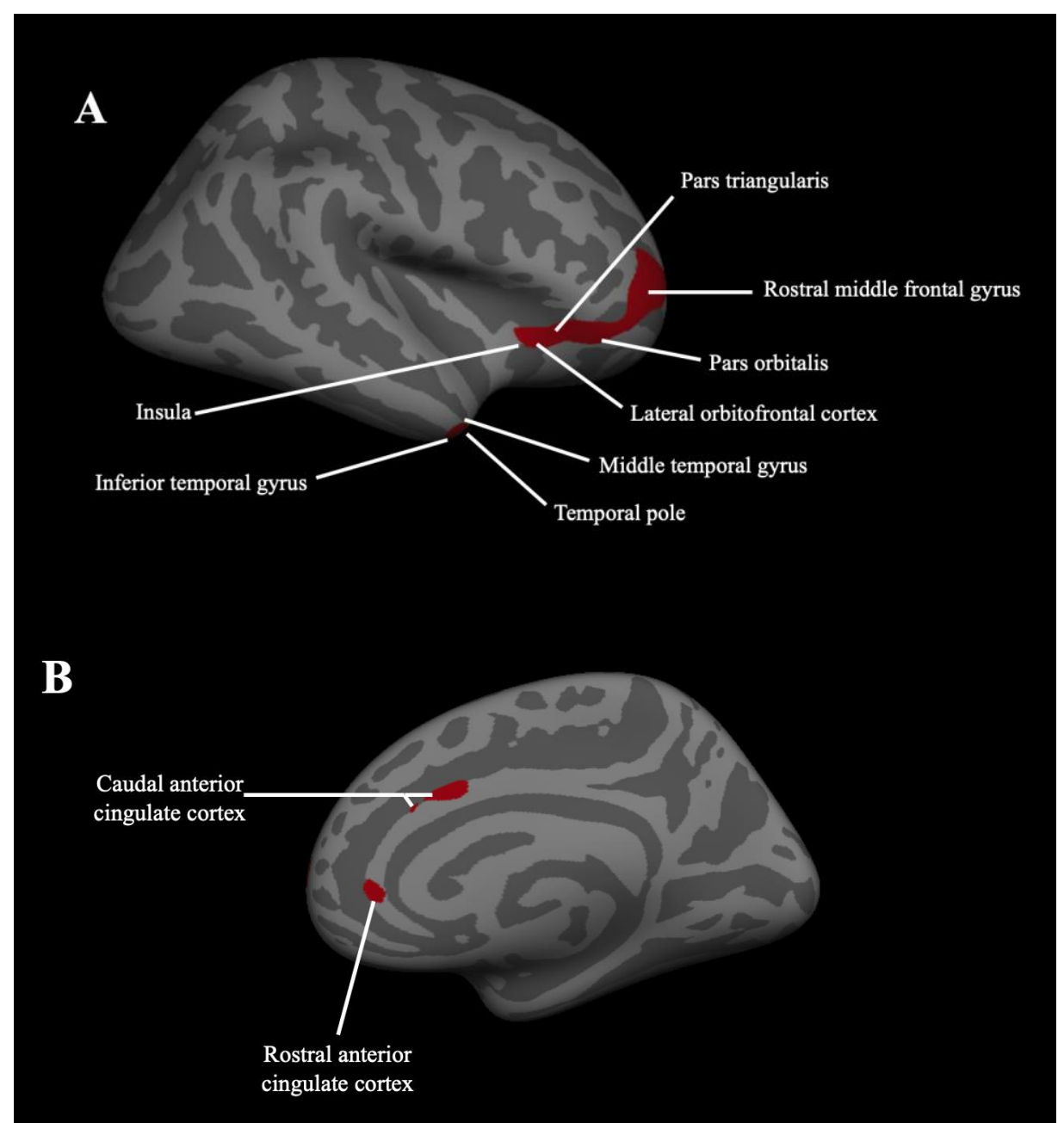

Figure 2. In red, significant associations between the surface area of the right hemisphere and physical symptoms from meta-analyses after correction for multiple testing $(\mathrm{N}=13,250)$. Panel A, lateral view. Panel B, medial view. 


\section{DISCUSSION}

Leveraging a dimensional approach for measuring (early signs) of physical symptoms in two independent and large cohorts of pre-adolescents from the general population, we found an association between subtle modifications of the surface area of the right hemisphere and physical symptoms. In line with the underpowered correlation paradox (Marek et al., 2020), the magnitude of the significant associations found in the present study was subtle and smaller than previously reported from small sample size studies. To have confirmed that there is an association between subtle alterations of the surface area of the right hemisphere and physical symptoms in the pre-adolescents general population is of relevance for, at least, two particular reasons (Dick et al., 2021). First, physical symptoms are better understood as a complex trait in which a combination of many smalleffect contributions are expected rather than large contributions for a few factors (Boyle et al., 2017). Second, these subtle effects may accumulate over childhood and adolescence imposing a burden for future health such as the development of disorders characterised by the presence of physical symptoms in adulthood (Wenar and Kerig, 2011).

In the present study, most of the significant associations with physical symptoms were located in hypothesised regions; i.e., mostly in the cingulate cortex and prefrontal cortex but also in the insula. A meta-analyses concluded that, in comparison to adults from the general population, those with somatoform disorders showed atypical features in the anterior cingulate cortex and prefrontal cortex (Boeckle et al., 2016). Additionally, a previous study showed that, in comparison to controls, adolescents with irritable bowel syndrome had lower grey matter volume in the cingulate cortex and prefrontal cortex (Bhatt et al., 2019). Among other functions, these two areas are related to cognitive and affective aspects of physical symptoms (Galambos et al., 2019; Johansen et al., 2001). Further longitudinal research is warranted to elucidate the temporality of the association observed from the present study. Particularly, to determine whether (i) children with a brain structure related to a worse cognitive and affective control are more prone to experience physical symptoms or (ii) to experience more physical symptoms led children to have a worse cognitive and affective control that impact in the structure of the brain. 
Some hypothesis of the present study were not confirmed. In particular, our findings are not in line with a previous study showing that children with complex regional pain syndrome, in comparison to control, had lower grey matter volume in the motor cortex (Erpelding et al., 2016). More recently, Pirwani et al., 2020 have compared brain structure of children and adolescents with persistent gastrointestinal symptoms and nonsymptomatic peers. The finding by Pirwani et al., 2020 also showed differences in the supplementary motor area. Interestingly, Pirwani et al., 2020 conducted complementary analyses stratifying the cases and controls by age range (i.e., pre-adolescents, adolescents and young adults with age ranges of 8 to 10,11 to 16 and 17 to 21 years old, respectively). Using this approach, they concluded that not all the differences in brain structure emerged for the pre-adolescent group (Pirwani et al., 2020). Considering that the developmental trajectory of grey matter volume typically follows an inverted U-shape (Giedd et al., 1996; Lenroot and Giedd, 2006), pre-adolescents participating in the present study may be at different stages of development resulting in a heterogeneous group regarding brain development. To corroborate this hypothesis, future longitudinal population-based research is warranted.

\section{Contribution of the present study to the field}

The design of the present study allows to better understand the association between brain structure and physical symptoms in pre-adolescents. A number of features of this study deserve attention. First, though physical symptoms lie on a continuum in the general population (Henningsen et al., 2007; Richardson and Engel, 2004; Wolfe et al., 2013), to the best of our knowledge, no study has previously investigated the association between physical symptoms dimensionally and brain structure in the general population. Second, previous studies mostly focused on children and adolescents diagnosed with a (chronic) disorder (i.e., irritable bowel syndrome (Bhatt et al., 2019; Hubbard et al., 2016)) or experiencing persistent physical symptoms (e.g., gastrointestinal symptoms (Pirwani et al., 2020)). In the present study, participants were recruited from the general population, which likely results in more generalisable findings. Third, we included two independent cohorts. Each of the cohorts included in the present study involved more than 2,000 participants, which is in line with the most recent rule-of-thumb recommendations to ensure the robustness and replicability of associations between brain and behaviour (Dick et al., 2021; Marek et al., 2020). 


\section{Strengths and limitations}

A number of limitations of the present study deserve attention. First, our cross-sectional design did not allow us to test the directionality of our findings. Second, the narrow range of age precludes the generalisation of the findings to younger or older ages. Third, as most of the epidemiological studies (Palermo et al., 2014), we only evaluated presence of the symptoms but not their impact. A more comprehensive assessments of physical symptoms may help to better understand the association under study. Third, because the information provided by different MRI modalities is complementary, future multi-modal neuroimaging studies are warranted to analyse different features of the brain such as its structure and function. In the context of physical symptoms in children and adolescents, to include both structural and functional MRI are of particular relevance (Palermo, 2020). An important strength of the present study is the inclusion of two cohorts. Although the cohorts were not fully harmonised, the same questionnaire was used to assess physical symptoms and similar methods were used to measure and analyse brain structure. Additional strengths are that the cohorts are ethnically diverse and from the general population and the study of physical symptoms along a continuum. Thus, as opposed to the previous literature in the field, the present study ensured a better generalisability of our findings in a broader context (Lewinn et al., 2017; Tiemeier and Muetzel, 2020).

\section{Conclusions}

Pooling data from two independent and large cohorts including a total of 13,250 preadolescents from the general population and using a dimensional approach for measuring (early signs) physical symptoms, we found cross-sectional associations between surface area of the right hemisphere and physical symptoms. These associations with physical symptoms were subtle and mostly emerged from regions related to cognitive and affective aspects of physical symptoms (e.g., the middle frontal gyrus and anterior cingulate cortex) and semantic memory (e.g., temporal pole). This is the first population neuroimaging of physical symptoms, that representative for adolescent populations in high income countries, and well-powered. Future longitudinal research is warranted to understand the longitudinal relationship of the associations under study. In particular, to elucidate whether subtle brain modifications are potential causes or consequences of physical symptoms. 


\section{Data and code availability statement}

The Generation $\mathrm{R}$ datasets generated and/or analysed during the current study are not publicly available due to legal and ethical regulations, but may be made available upon request to the Director of the Generation $\mathrm{R}$ Study, Vincent Jaddoe (v.jaddoe@erasmusmc.nl), in accordance with the local, national, and European Union regulations.

The ABCD data repository grows and changes over time. The ABCD data used in this report came from the ABCD Data Release 2.0 (DOI: 10.15154/1503209, March 2019) and ABCD Fix Release 2.0.1 (DOI: 10.15154/1504041, July 2019).

\section{Funding}

F.E.-L. and M.L.-V. received funding from the European Union's Horizon 2020 research and innovation programme under the Marie Skłodowska-Curie (grant agreement No 707404). H.T. was supported by a grant of the Netherlands Organization for Scientific Research (NWO/ZonMW grant 016.VICI.170.200). Neuroimaging analysis and infrastructure were supported by the Sophia Research Foundation (S18-20) and the Erasmus University Fellowship (to R.L.M.). The general design of the Generation R Study is made possible by financial support from the Erasmus Medical Center, Rotterdam, the Erasmus University Rotterdam, ZonMw, the Netherlands Organisation for Scientific Research (NWO), and the Ministry of Health, Welfare and Sport.

The opinions expressed in this document reflect only the author's view. The European Commission is not responsible for any use that may be made of the information it contains. The ABCD Study is supported by the National Institutes of Health and additional federal partners under award numbers U01DA041022, U01DA041028, U01DA041048, U01DA041089, U01DA041106, U01DA041117, U01DA041120, U01DA041134，U01DA041148，U01DA041156，U01DA041174，U24DA041025, U01DA041093, U24DA041123, and U24DA041147. A full list of supporters is available at https://abcdstudy.org/nih-collaborators.

None of the funding agencies were involved in the study design; the collection, analysis and interpretation of data; in the writing of the report; nor in the decision to submit the article for publication. This manuscript reflects the views of the authors and may not 
reflect the opinions or views of the funding agencies or investigators in the included cohorts.

\section{Authorship contribution statement}

F.E.-L.: Conceptualization, Methodology, Formal analysis, Writing - Original Draft, Visualization, Funding acquisition, Project administration. H.H.K.: Formal analysis, Writing - Review \& Editing. M.L.-V.: Writing - Review \& Editing, Funding acquisition. J.S.L.: Writing - Review \& Editing. M.H.J.H.: Writing - Review \& Editing, Supervision, Project administration, Funding acquisition. H.T.: Writing - Review \& Editing, Supervision, Project administration, unding acquisition. R.L.M: Conceptualization, Methodology, Software, Formal analysis, Writing - Original Draft, Supervision, Project administration, Funding acquisition.

\section{Declaration of Competing Interest}

None

\section{Acknowledgements}

The Generation R Study is conducted by the Erasmus Medical Center in close collaboration with Faculty of Social Sciences of the Erasmus University Rotterdam, the Municipal Health Service Rotterdam area, Rotterdam, and the Stichting Trombosedienst \& Artsenlaboratorium Rijnmond (STAR-MDC), Rotterdam. We gratefully acknowledge the contribution of children and parents, general practitioners, hospitals, midwives, and pharmacies in Rotterdam.

A listing of the ABCD consortium participating sites and a complete listing of the study investigators can be found at https://abcdstudy.org/principal-investigators.html. ABCD consortium investigators designed and implemented the study and/or provided data but did not necessarily participate in analysis or writing of this report. 


\section{REFERENCES}

Achenbach, T., Rescorla, L., 2000. Manual for the ASEBA preschool forms and profiles. VT: University of Vermont, Research Center for Children, Youth, \& Families, Burlington, VT.

Basten, M., van der Ende, J., Tiemeier, H., Althoff, R.R., Rijlaarsdam, J., Jaddoe, V.W. V., Hofman, A., Hudziak, J.J., Verhulst, F.C., White, T., 2014. Nonverbal intelligence in young children with dysregulation: the Generation R Study. Eur. Child Adolesc. Psychiatry 23, 1061-1070. https://doi.org/10.1007/s00787-0140551-x

Berntsson, L.T., Köhler, L., 2001. Long-term illness and psychosomatic complaints in children aged 2-17 years in the five Nordic countries. Comparison between 1984 and 1996. Eur. J. Public Health 11, 35-42. https://doi.org/10.1093/eurpub/11.1.35

Bhatt, R.R., Gupta, A., Labus, J.S., Zeltzer, L.K., Tsao, J.C., Shulman, R.J., Tillisch, K., 2019. Altered Brain Structure and Functional Connectivity and Its Relation to Pain Perception in Girls With Irritable Bowel Syndrome. Psychosom. Med. 81, 146-154. https://doi.org/10.1097/PSY.0000000000000655

Boeckle, M., Schrimpf, M., Liegl, G., Pieh, C., 2016. Neural correlates of somatoform disorders from a meta-analytic perspective on neuroimaging studies. NeuroImage. Clin. 11, 606-613. https://doi.org/10.1016/j.nicl.2016.04.001

Bourke, J.H., Langford, R.M., White, P.D., 2015. The common link between functional somatic syndromes may be central sensitisation. J. Psychosom. Res. 78, 228-36. https://doi.org/10.1016/j.jpsychores.2015.01.003

Boyle, E.A., Li, Y.I., Pritchard, J.K., 2017. An Expanded View of Complex Traits: From $\begin{array}{llll}\text { Polygenic to } \quad \text { Omnigenic. } & \text { Cell }\end{array}$ https://doi.org/10.1016/j.cell.2017.05.038

Casey, B.J., Cannonier, T., Conley, M.I., Cohen, A.O., Barch, D.M., Heitzeg, M.M., Soules, M.E., Teslovich, T., Dellarco, D. V., Garavan, H., Orr, C.A., Wager, T.D., Banich, M.T., Speer, N.K., Sutherland, M.T., Riedel, M.C., Dick, A.S., Bjork, J.M., Thomas, K.M., Chaarani, B., Mejia, M.H., Hagler, D.J., Daniela Cornejo, M., Sicat, C.S., Harms, M.P., Dosenbach, N.U.F., Rosenberg, M., Earl, E., Bartsch, H., Watts, R., Polimeni, J.R., Kuperman, J.M., Fair, D.A., Dale, A.M., 2018. The Adolescent 
Brain Cognitive Development (ABCD) study: Imaging acquisition across 21 sites. Dev. Cogn. Neurosci. https://doi.org/10.1016/j.den.2018.03.001

Creed, F., Guthrie, E., Fink, P., Henningsen, P., Rief, W., Sharpe, M., White, P., 2010. Is there a better term than "Medically unexplained symptoms"? J. Psychosom. Res. 68, 5-8. https://doi.org/10.1016/j.jpsychores.2009.09.004

den Boer, C., Dries, L., Terluin, B., van der Wouden, J.C., Blankenstein, A.H., van Wilgen, C.P., Lucassen, P., van der Horst, H.E., 2019. Central sensitization in chronic pain and medically unexplained symptom research: A systematic review of definitions, operationalizations and measurement instruments. J. Psychosom. Res. 117, 32-40. https://doi.org/10.1016/j.jpsychores.2018.12.010

Desikan, R.S., Ségonne, F., Fischl, B., Quinn, B.T., Dickerson, B.C., Blacker, D., Buckner, R.L., Dale, A.M., Maguire, R.P., Hyman, B.T., Albert, M.S., Killiany, R.J., 2006. An automated labeling system for subdividing the human cerebral cortex on MRI scans into gyral based regions of interest. Neuroimage 31, 968-80. https://doi.org/10.1016/j.neuroimage.2006.01.021

Dick, A.S., Lopez, D.A., Watts, A.L., Heeringa, S., Reuter, C., Bartsch, H., Fan, C.C., Kennedy, D.N., Palmer, C., Marshall, A., Haist, F., Hawes, S., Nichols, T.E., Barch, D.M., Jernigan, T.L., Garavan, H., Grant, S., Pariyadath, V., Hoffman, E., Neale, M., Stuart, E.A., Paulus, M.P., Sher, K.J., Thompson, W.K., 2021. Meaningful Associations in the Adolescent Brain Cognitive Development Study. bioRxiv 1-75. https://doi.org/10.1101/2020.09.01.276451

Erpelding, N., Simons, L., Lebel, A., Serrano, P., Pielech, M., Prabhu, S., Becerra, L., Borsook, D., 2016. Rapid treatment-induced brain changes in pediatric CRPS. Brain Struct. Funct. 221, 1095-111. https://doi.org/10.1007/s00429-014-0957-8

Fischl, B., 2012. FreeSurfer. Neuroimage 62, 774-781. https://doi.org/10.1016/j.neuroimage.2012.01.021

Fischl, B., Salat, D.H., Busa, E., Albert, M., Dieterich, M., Haselgrove, C., van der Kouwe, A., Killiany, R., Kennedy, D., Klaveness, S., Montillo, A., Makris, N., Rosen, B., Dale, A.M., 2002. Whole brain segmentation: automated labeling of neuroanatomical structures in the human brain. Neuron 33, 341-55. https://doi.org/10.1016/s0896-6273(02)00569-х

Galambos, A., Szabó, E., Nagy, Z., Édes, A.E., Kocsel, N., Juhász, G., Kökönyei, G., 
2019. A systematic review of structural and functional MRI studies on pain catastrophizing. J. Pain Res. Volume 12, 1155-1178. https://doi.org/10.2147/JPR.S192246

Garavan, H., Bartsch, H., Conway, K., Decastro, A., Goldstein, R.Z., Heeringa, S., Jernigan, T., Potter, A., Thompson, W., Zahs, D., 2018. Recruiting the ABCD sample: Design considerations and procedures. Dev. Cogn. Neurosci. 32, 16-22. https://doi.org/10.1016/j.den.2018.04.004

Giedd, J.N., Vaituzis, A.C., Hamburger, S.D., Lange, N., Rajapakse, J.C., Kaysen, D., Vauss, Y.C., Rapoport, J.L., 1996. Quantitative MRI of the temporal lobe, amygdala, and hippocampus in normal human development: Ages 4-18 years. J. Comp. Neurol. 366, 223-230. https://doi.org/10.1002/(SICI)10969861(19960304)366:2<223::AID-CNE3>3.0.CO;2-7

Greve, D.N., Fischl, B., 2018. False positive rates in surface-based anatomical analysis. Neuroimage 171, 6-14. https://doi.org/10.1016/j.neuroimage.2017.12.072

Groenewald, C.B., Essner, B.S., Wright, D., Fesinmeyer, M.D., Palermo, T.M., 2014. The economic costs of chronic pain among a cohort of treatment-seeking adolescents in the United States. J. Pain 15, 925-33. https://doi.org/10.1016/j.jpain.2014.06.002

Gubbels, J., van der Put, C.E., Assink, M., 2019. Risk Factors for School Absenteeism and Dropout: A Meta-Analytic Review. J. Youth Adolesc. 48, 1637-1667. https://doi.org/10.1007/s10964-019-01072-5

Hagler, D.J., Hatton, S., Cornejo, M.D., Makowski, C., Fair, D.A., Dick, A.S., Sutherland, M.T., Casey, B.J., Barch, D.M., Harms, M.P., Watts, R., Bjork, J.M., Garavan, H.P., Hilmer, L., Pung, C.J., Sicat, C.S., Kuperman, J., Bartsch, H., Xue, F., Heitzeg, M.M., Laird, A.R., Trinh, T.T., Gonzalez, R., Tapert, S.F., Riedel, M.C., Squeglia, L.M., Hyde, L.W., Rosenberg, M.D., Earl, E.A., Howlett, K.D., Baker, F.C., Soules, M., Diaz, J., de Leon, O.R., Thompson, W.K., Neale, M.C., Herting, M., Sowell, E.R., Alvarez, R.P., Hawes, S.W., Sanchez, M., Bodurka, J., Breslin, F.J., Morris, A.S., Paulus, M.P., Simmons, W.K., Polimeni, J.R., van der Kouwe, A., Nencka, A.S., Gray, K.M., Pierpaoli, C., Matochik, J.A., Noronha, A., Aklin, W.M., Conway, K., Glantz, M., Hoffman, E., Little, R., Lopez, M., Pariyadath, V., Weiss, S.R., Wolff-Hughes, D.L., DelCarmen-Wiggins, R., Feldstein Ewing, S.W., Miranda-Dominguez, O., Nagel, B.J., Perrone, A.J., Sturgeon, D.T., Goldstone, A., 
Pfefferbaum, A., Pohl, K.M., Prouty, D., Uban, K., Bookheimer, S.Y., Dapretto, M., Galvan, A., Bagot, K., Giedd, J., Infante, M.A., Jacobus, J., Patrick, K., Shilling, P.D., Desikan, R., Li, Y., Sugrue, L., Banich, M.T., Friedman, N., Hewitt, J.K., Hopfer, C., Sakai, J., Tanabe, J., Cottler, L.B., Nixon, S.J., Chang, L., Cloak, C., Ernst, T., Reeves, G., Kennedy, D.N., Heeringa, S., Peltier, S., Schulenberg, J., Sripada, C., Zucker, R.A., Iacono, W.G., Luciana, M., Calabro, F.J., Clark, D.B., Lewis, D.A., Luna, B., Schirda, C., Brima, T., Foxe, J.J., Freedman, E.G., Mruzek, D.W., Mason, M.J., Huber, R., McGlade, E., Prescot, A., Renshaw, P.F., YurgelunTodd, D.A., Allgaier, N.A., Dumas, J.A., Ivanova, M., Potter, A., Florsheim, P., Larson, C., Lisdahl, K., Charness, M.E., Fuemmeler, B., Hettema, J.M., Maes, H.H., Steinberg, J., Anokhin, A.P., Glaser, P., Heath, A.C., Madden, P.A., BaskinSommers, A., Constable, R.T., Grant, S.J., Dowling, G.J., Brown, S.A., Jernigan, T.L., Dale, A.M., 2019. Image processing and analysis methods for the Adolescent

Brain Cognitive Development Study. Neuroimage 202, 116091. https://doi.org/10.1016/j.neuroimage.2019.116091

Hagler, D.J., Saygin, A.P., Sereno, M.I., 2006. Smoothing and cluster thresholding for cortical surface-based group analysis of fMRI data. Neuroimage 33, 1093-1103. https://doi.org/10.1016/j.neuroimage.2006.07.036

Henningsen, P., Zipfel, S., Herzog, W., 2007. Management of functional somatic syndromes. Lancet 369, 946-955. https://doi.org/10.1016/S0140-6736(07)60159-7

Hubbard, C.S., Becerra, L., Heinz, N., Ludwick, A., Rasooly, T., Wu, R., Johnson, A., Schechter, N.L., Borsook, D., Nurko, S., 2016. Abdominal Pain, the Adolescent and Altered Brain Structure and Function. PLoS One 11, e0156545. https://doi.org/10.1371/journal.pone.0156545

Ivanova, M.Y., Achenbach, T.M., Rescorla, L.A., Harder, V.S., Ang, R.P., Bilenberg, N., Bjarnadottir, G., Capron, C., De Pauw, S.S., Dias, P., Dobrean, A., Doepfner, M., Duyme, M., Eapen, V., Erol, N., Esmaeili, E.M., Ezpeleta, L., Frigerio, A., Gonçalves, M.M., Gudmundsson, H.S., Jeng, S.-F., Jetishi, P., Jusiene, R., Kim, Y.A., Kristensen, S., Lecannelier, F., Leung, P.W., Liu, J., Montirosso, R., Oh, K.J., Plueck, J., Pomalima, R., Shahini, M., Silva, J.R., Simsek, Z., Sourander, A., Valverde, J., Van Leeuwen, K.G., Woo, B.S., Wu, Y.-T., Zubrick, S.R., Verhulst, F.C., 2010. Preschool Psychopathology Reported by Parents in 23 Societies: Testing the Seven-Syndrome Model of the Child Behavior Checklist for Ages 1.5-5. J. Am. 
Acad. Child Adolesc. Psychiatry 49, 1215-1224. https://doi.org/10.1016/j.jaac.2010.08.019

Johansen, J.P., Fields, H.L., Manning, B.H., 2001. The affective component of pain in rodents: direct evidence for a contribution of the anterior cingulate cortex. Proc. Natl. Acad. Sci. U. S. A. 98, 8077-82. https://doi.org/10.1073/pnas.141218998

Kooijman, M.N., Kruithof, C.J., van Duijn, C.M., Duijts, L., Franco, O.H., van IJzendoorn, M.H., de Jongste, J.C., Klaver, C.C.W., van der Lugt, A., Mackenbach, J.P., Moll, H.A., Peeters, R.P., Raat, H., Rings, E.H.H.M., Rivadeneira, F., van der Schroeff, M.P., Steegers, E.A.P., Tiemeier, H., Uitterlinden, A.G., Verhulst, F.C., Wolvius, E., Felix, J.F., Jaddoe, V.W. V., 2016. The Generation R Study: design and cohort update 2017. Eur. J. Epidemiol. 31, 1243-1264. https://doi.org/10.1007/s10654-016-0224-9

Kutch, J.J., Ichesco, E., Hampson, J.P., Labus, J.S., Farmer, M.A., Martucci, K.T., Ness, T.J., Deutsch, G., Apkarian, A.V., Mackey, S.C., Klumpp, D.J., Schaeffer, A.J., Rodriguez, L. V., Kreder, K.J., Buchwald, D., Andriole, G.L., Lai, H.H., Mullins, C., Kusek, J.W., Landis, J.R., Mayer, E.A., Clemens, J.Q., Clauw, D.J., Harris, R.E., 2017. Brain signature and functional impact of centralized pain: a multidisciplinary approach to the study of chronic pelvic pain (MAPP) network study. Pain 158, 19791991. https://doi.org/10.1097/j.pain.0000000000001001

Lamballais, S., Muetzel, R.L., 2021. QDECR: A Flexible, Extensible Vertex-Wise Analysis Framework in R. Front. Neuroinform. 15, 14. https://doi.org/10.3389/fninf.2021.561689

Lenroot, R.K., Giedd, J.N., 2006. Brain development in children and adolescents: insights from anatomical magnetic resonance imaging. Neurosci. Biobehav. Rev. 30, 71829. https://doi.org/10.1016/j.neubiorev.2006.06.001

Lewinn, K.Z., Sheridan, M.A., Keyes, K.M., Hamilton, A., McLaughlin, K.A., 2017. Sample composition alters associations between age and brain structure. Nat. Commun. 8. https://doi.org/10.1038/s41467-017-00908-7

Marek, S., Tervo-Clemmens, B., Calabro, F.J., Montez, D.F., Kay, B.P., Hatoum, A.S., Rose Donohue, M., Foran, W., Miller, R.L., Feczko, E., Miranda-Dominguez, O., Graham, A.M., Chen, J., Newbold, D.J., Zheng, A., Seider, N.A., Van, A.N., Laumann, T.O., Thompson, W.K., Greene, D.J., Petersen, S.E., Nichols, T.E., 
Thomas Yeo, B., Barch, D.M., Garavan, H., Luna, B., Fair, D.A., Dosenbach, N., 2020. Towards Reproducible Brain-Wide Association Studies Affiliations. bioRxiv 1-40. https://doi.org/10.1101/2020.08.21.257758

Muetzel, R.L., Mulder, R.H., Lamballais, S., Cortes Hidalgo, A.P., Jansen, P., Güroğlu, B., Vernooiji, M.W., Hillegers, M., White, T., El Marroun, H., Tiemeier, H., 2019. Frequent Bullying Involvement and Brain Morphology in Children. Front. Psychiatry 10, 696. https://doi.org/10.3389/fpsyt.2019.00696

Palermo, T.M., 2020. Pain prevention and management must begin in childhood: the key role of psychological interventions. Pain 161, S114-S121. https://doi.org/10.1097/j.pain.0000000000001862

Palermo, T.M., Valrie, C.R., Karlson, C.W., 2014. Family and parent influences on pediatric chronic pain: A developmental perspective. Am. Psychol. 69, 142-152. https://doi.org/10.1037/a0035216

Pirwani, A.F., Fang, Z., Li, B., Smith, A., Northoff, G., Ismail, N., 2020. The effects of gastrointestinal symptoms on structural gray matter volume in youth. Int. J. Dev. Neurosci. 1-12. https://doi.org/10.1002/jdn.10044

Raznahan, A., Shaw, P., Lalonde, F., Stockman, M., Wallace, G.L., Greenstein, D., Clasen, L., Gogtay, N., Giedd, J.N., 2011. How does your cortex grow? J. Neurosci. 31, 7174-7177. https://doi.org/10.1523/JNEUROSCI.0054-11.2011

Richardson, R.D., Engel, C.C., 2004. Evaluation and management of medically unexplained physical symptoms. Neurologist 10, 18-30. https://doi.org/10.1097/01.nrl.0000106921.76055.24

Rubin, D., 2004. Multiple imputation for nonresponse in surveys. John Wiley \& Sons.

Tiemeier, H., Muetzel, R.L., 2020. Population Neuroscience, in: Taylor, E., Verhulst, F.C., Wong, J., Yoshida, K. (Eds.), Mental Health and Illness of Children and Adolescents. Springer, Singapore, p. 715.

van Buuren, S., Groothuis-Oudshoorn, K., 2011. mice: Multivariate imputation by chained equations in R. J. Stat. Softw. 45, 1-67. https://doi.org/10.18637/jss.v045.i03

Volkow, N.D., Koob, G.F., Croyle, R.T., Bianchi, D.W., Gordon, J.A., Koroshetz, W.J., Pérez-Stable, E.J., Riley, W.T., Bloch, M.H., Conway, K., Deeds, B.G., Dowling, 
G.J., Grant, S., Howlett, K.D., Matochik, J.A., Morgan, G.D., Murray, M.M., Noronha, A., Spong, C.Y., Wargo, E.M., Warren, K.R., Weiss, S.R.B.B., 2018. The conception of the ABCD study: From substance use to a broad NIH collaboration. Dev. Cogn. Neurosci. 32, 4-7. https://doi.org/10.1016/j.dcn.2017.10.002

Wenar, C., Kerig, P., 2011. Developmental Psychopathology: From Infancy Through Adolescence. McGraw Hill.

White, T., Muetzel, R.L., El Marroun, H., Blanken, L.M.E., Jansen, P., Bolhuis, K., Kocevska, D., Mous, S.E., Mulder, R., Jaddoe, V.W. V., van der Lugt, A., Verhulst, F.C., Tiemeier, H., 2018. Paediatric population neuroimaging and the Generation R Study: the second wave. Eur. J. Epidemiol. 33, 99-125. https://doi.org/10.1007/s10654-017-0319-y

Wolfe, F., Brähler, E., Hinz, A., Häuser, W., 2013. Fibromyalgia prevalence, somatic symptom reporting, and the dimensionality of polysymptomatic distress: results from a survey of the general population. Arthritis Care Res. (Hoboken). 65, 777-85. https://doi.org/10.1002/acr.21931 